\title{
A Very Rare Coronary Artery Anomaly: Two Circumflex Arteries Originating From Both Right and Left Coronary Sinuses of Valsalva
}

\author{
Mehmet Demir $^{\mathrm{a}, \mathrm{b}}$, Ahmet Tutuncu ${ }^{\mathrm{a}}$, Alper Karakus ${ }^{\mathrm{a}}$
}

\begin{abstract}
Coronary anomalies are found in less than $1 \%$ of diagnostic coronary angiograms. The clinical importance of coronary anomalies varies from insignificant to life-threatening. We report a very rare case of a patient with two circumflex arteries originating from both right and left coronary sinuses of Valsalva.
\end{abstract}

Keywords: Coronary artery anomalies; Twin circumflex arteries; Right sinus of Valsalva

\section{Introduction}

Coronary artery anomalies have been identified in $0.6-1.5 \%$ of coronary angiograms in the general population. The importance of coronary anomalies varies from unimportant to lifethreatening [1-3].

\section{Case Report}

A 52-year-old hypertensive man with a history of chest discomfort was referred to our clinic. His physical examination, echocardiogram, and electrocardiogram reports were all normal. Following physical examination and initial tests, a diagnostic coronary arteriography was performed. Left coronary arteriography revealed a normal left main coronary artery (LMCA) originating from the left sinus of Valsalva. The LMCA was branching into the left anterior descending (LAD) and left circumflex (Cx) arteries (Fig. 1).

When the right coronary ostium was cannulated, another

\section{Manuscript accepted for publication February 24, 2015}

aBursa Yuksek Ihtisas Education and Research Hospital Cardiology Department, Bursa, Turkey

${ }^{\mathrm{b}}$ Corresponding Author: Mehmet Demir, Bursa Yuksek Ihtisas Education and Research Hospital Cardiology Department, Bursa, Turkey.

Email:drmehmetd@gmail.com

doi: http://dx.doi.org/10.14740/cr381w
$\mathrm{Cx}$ artery was noticed in addition to a right coronary artery (RCA) (Fig. 2: RCA and Fig. 3: Cx).

The coronary arteries were found to be normal and the patient was discharged without any complication.

\section{Discussion}

The most frequently found anomalies include a Cx artery with a separate ostium from the LAD originating in the left coronary cusp, an origin of the Cx artery taking off from the RCA or arising separately from the right coronary cusp [1-3].

To our knowledge, the case of tricircumflex arteries originating from both right and left coronary sinuses of Valsalva has been previously only two times reported [4-6].

The most important problem in diagnosing double $\mathrm{Cx}$ arteries is the separate origin of the two $\mathrm{Cx}$ arteries from different ostia on the left or right aortic sinus of Valsalva. Thus, the angiographer must always keep in mind this possibility.

To our knowledge, an aberrant accessory but normal $\mathrm{Cx}$ artery has no clinical significance. However, the clinical significance of the anomaly may be important in patients undergoing coronary intervention or cardiac surgery.

A Cx artery arising from the main stem and an anomalous $\mathrm{Cx}$ artery from right sinus of Valsalva has been previously reported three times [4-6].

As a fourth we report two circumflex arteries originating

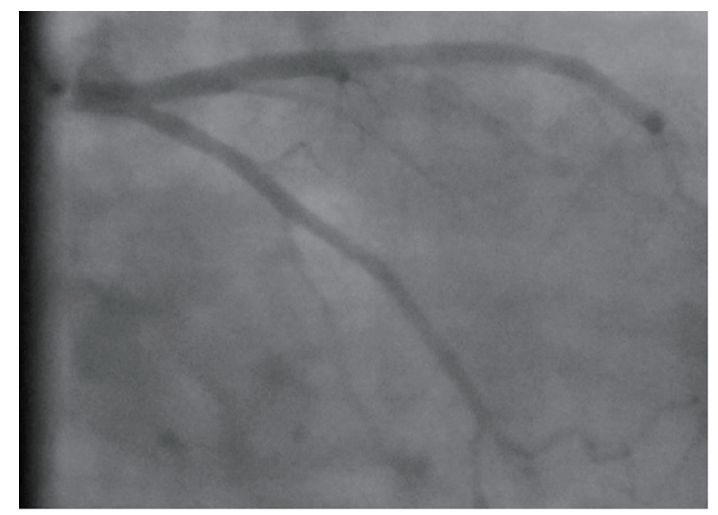

Figure 1. Coronary angiogram in the right caudal view shows the left coronary artery tree with a circumflex artery. 


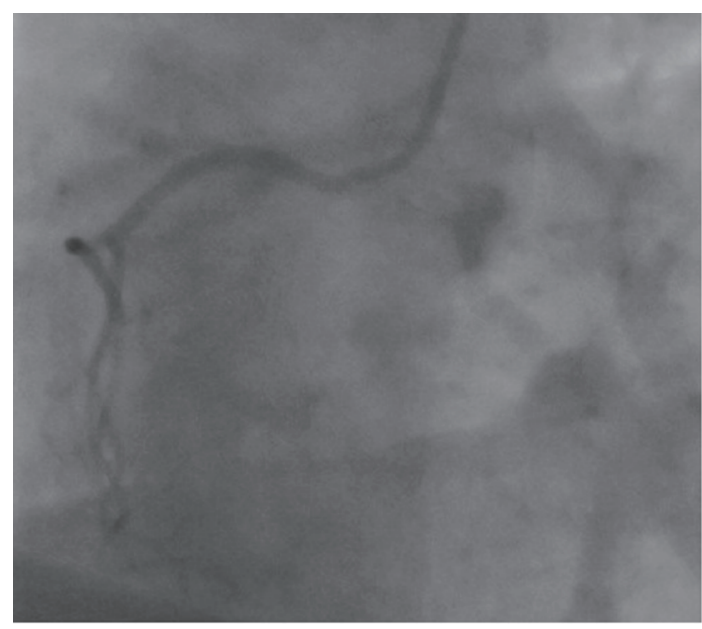

Figure 2. Coronary angiogram in the left anterior oblique cranial view shows the right coronary artery originating from right sinus of Valsalva.

from both right and left coronary sinuses of Valsalva in this case.

\section{References}

1. Yamanaka O, Hobbs RE. Coronary artery anomalies in 126,595 patients undergoing coronary arteriography. Cathet Cardiovasc Diagn. 1990;21(1):28-40.

2. Wilkins CE, Betancourt B, Mathur VS, Massumi A, De Castro CM, Garcia E, Hall RJ. Coronary artery anomalies: a review of more than 10,000 patients from the Clayton Cardiovascular Laboratories. Tex Heart Inst J. 1988;15(3):166-173.

3. Angelini P, Villason S, Chan AV Jr, et al. Normal and

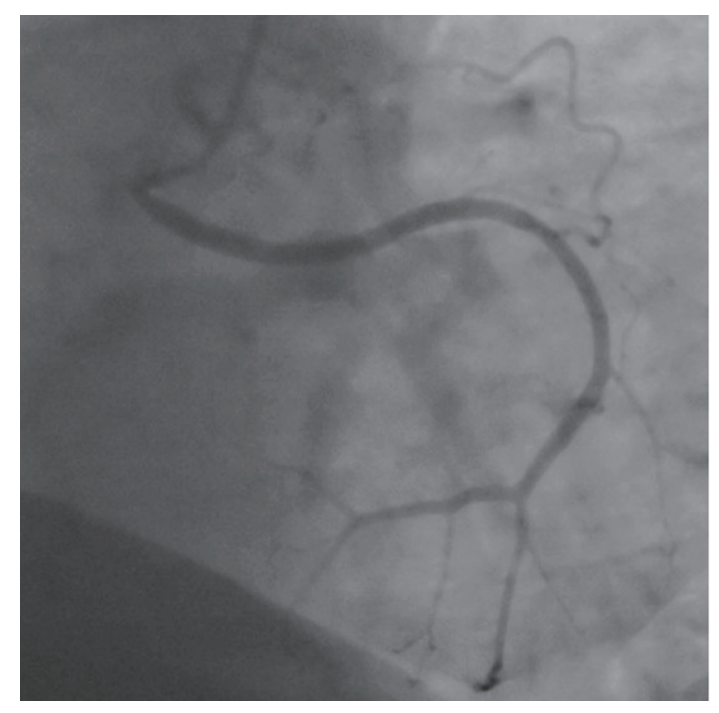

Figure 3. Coronary angiogram in the left anterior oblique cranial view shows the circumflex artery originating from right sinus of Valsalva.

anomalous coronary arteries in humans. In: Angelini P, ed. Coronary Artery Anomalies: A Comprehensive Approach. Philadelphia, PA: Lippincott Williams \& Wilkins; 1999:27-79.

4. van der Velden LB, Bar FW, Meursing BT, Ophuis TJ. A rare combination of coronary anomalies. Neth Heart J. 2008;16(11):387-389.

5. Ulucay A, Celkan MA, Aksoy MF. Two circumflex arteries originating from both right and left coronary sinuses of Valsalva. Neth Heart J. 2013;21(7-8):373.

6. Attar MN, Moore RK, Khan S. Twin circumflex arteries: a rare coronary artery anomaly. J Invasive Cardiol. 2008;20(2):E54-55. 